\title{
Energy-Efficient Building Retrofits: An Assessment of Regulatory Proposals under Uncertainty
}

\author{
Paula Rocha ${ }^{\mathrm{a}}$, Michal Kaut ${ }^{\mathrm{b}}$, Afzal S. Siddiqui ${ }^{\mathrm{a}, \mathrm{c}, *}$ \\ ${ }^{a}$ Department of Statistical Science, University College London, London, United Kingdom \\ ${ }^{b}$ Department of Applied Economics, SINTEF Technology and Society, Trondheim, \\ Norway \\ ${ }^{c}$ Department of Computer and Systems Sciences, Stockholm University, Stockholm, \\ Sweden
}

\begin{abstract}
Improving energy efficiency in European Union buildings will require retrofitting much of the existing stock due to limited new construction opportunities. Given uncertainty in energy prices and technology costs stemming from deregulation, a stochastic optimisation framework is desirable for long-term decision support. We synthesise treatment of uncertainty and risk management to obtain insights about the impact of retrofits on energy consumption, costs, $\mathrm{CO}_{2}$ emissions, and risk at real buildings in Austria and Spain. The optimal strategy for the Spanish site is to invest in photovoltaic and solar thermal technologies. This lowers expected costs by $8.5 \%$ and reduces expected primary energy consumption and $\mathrm{CO}_{2}$ emissions by $20 \%$ relative to using existing equipment. By limiting exposure to volatile energy prices, the strategy also yields a nearly $10 \%$ reduction in risk. We obtain similar results also for the Austrian site. Via this framework, tradeoffs among competing objectives and the effectiveness of proposed regulation may be assessed. Specifically, we find that more stringent restrictions on energy efficiency are economically viable if regulation also facilitates enhanced operational decision support for buildings. Indeed, primary energy consumption can be lowered only through more on-site generation such as combined heat and power, which is more complex for building managers to deploy.
\end{abstract}

\footnotetext{
*Corresponding author. Tel.: +44 2076791871

Email addresses: p.rocha@ucl.ac.uk (Paula Rocha), michal.kaut@sintef.no (Michal Kaut), afzal.siddiqui@ucl.ac.uk (Afzal S. Siddiqui)
} 
Keywords: Long-term planning for buildings, Energy efficiency in buildings, Risk management of buildings, Stochastic programming

\section{Introduction}

In order to transition towards a more sustainable economy, drastic changes in both the supply and demand sides of the energy sector are required. The former have been taking place prominently with greater adoption of renewable energy technologies driven by support from policy measures, viz., capand-trade systems, feed-in tariffs (FiT), renewable portfolio standards, and subsidies. In Germany, for example, such measures have resulted in a transformation of the power sector, i.e., the Energiewende, with the share of renewables having risen to nearly $30 \%$ of electricity consumption in the year 2013 (compared to less than $5 \%$ in 1990) and a $25 \%$ reduction in $\mathrm{CO}_{2}$ emissions over the same period (von Hirschhausen, 2014). Chen and Wang (2013) and Woodman and Mitchell (2011) provide a comprehensive assessment of the effectiveness of similar support schemes. However, often missing from such analyses is the role of the demand side in enabling a sustainable energy transition (Strbac, 2008). Indeed, in the EU, $40 \%$ of all energy consumed is by buildings (EC, 2010), which makes it desirable for policymakers to devise incentives for building owners to improve the efficiency of their stock (Georgopoulou et al., 2006).

Given the relatively low level of new construction starts in OECD countries, improving energy efficiency at the building level typically involves improved operations of existing equipment (Groissböck et al., 2014; Liang et al., 2012) or retrofits (Cano et al., 2014; Kumbaroğlu and Madlener, 2012). Confounding this task is the fact that energy sectors in most OECD countries have been deregulated over the past thirty years (Wilson, 2002). Instead of facing stable regulated rates as in the era of vertically integrated utilities, consumers are now likely to see frequent changes in the electricity and fuel prices that they are charged. Furthermore, the pace of technological innovation spurred by deregulation adds uncertainty to the performance characteristics of forthcoming equipment types. Combined with the complexity of energy flows at the building level, e.g., in terms of operating complementarities between heating and power applications, such uncertainty and exposure to risk may make it difficult for building owners to make sound equipmentreplacement decisions. In order to provide them with better decision support 


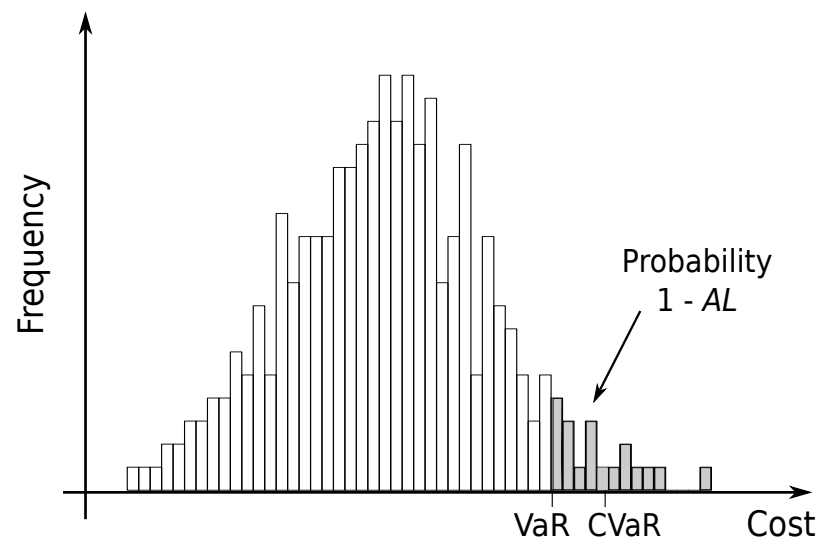

Figure 1: Conditional Value-at-Risk Illustration

and to investigate the implications of alternative policy measures in inducing investment at the building level, we implement a stochastic programming model (e.g., Kall and Wallace, 1994; Birge and Louveaux, 1997; Conejo et al., 2010) for the long-term investment and retrofitting problems facing real buildings.

Vis-à-vis most optimisation-based analyses of investment in distributed energy resources (DER), e.g., King and Morgan (2007), Marnay et al. (2008), Omu et al. (2013), Stadler et al. (2011), and Ashouri et al. (2013), stochastic programming enables the assessment of decisions made under uncertainty. Other work, such as Maribu and Fleten (2008) and Siddiqui and Maribu (2009), takes a real options approach to examine the role of investment timing and technology choice under uncertainty. However, the risk exposure of the decision maker is not considered directly and may be evaluated only ex post. By contrast, the stochastic programming approach not only accounts for future uncertainty in energy prices and technology costs via discrete scenarios but also allows for inclusion of coherent risk measures such as the conditional value-at-risk (CVaR), introduced by Rockafellar and Uryasev (2000). For continuous distributions, CVaR is equal to the expected value of the worst $(1-A L) \times 100 \%$ outcomes (Figure 1$)$, where $A L$ is a confidence level, typically chosen to be 0.95 or 0.99 . The concept can be generalised for discrete distributions using only linear constraints (Rockafellar and Uryasev, 2002), thereby making CVaR a popular risk measure within the optimisation community.

From the perspective of a building owner, the profitability of new energy technologies will depend on their performance, which will be influenced 


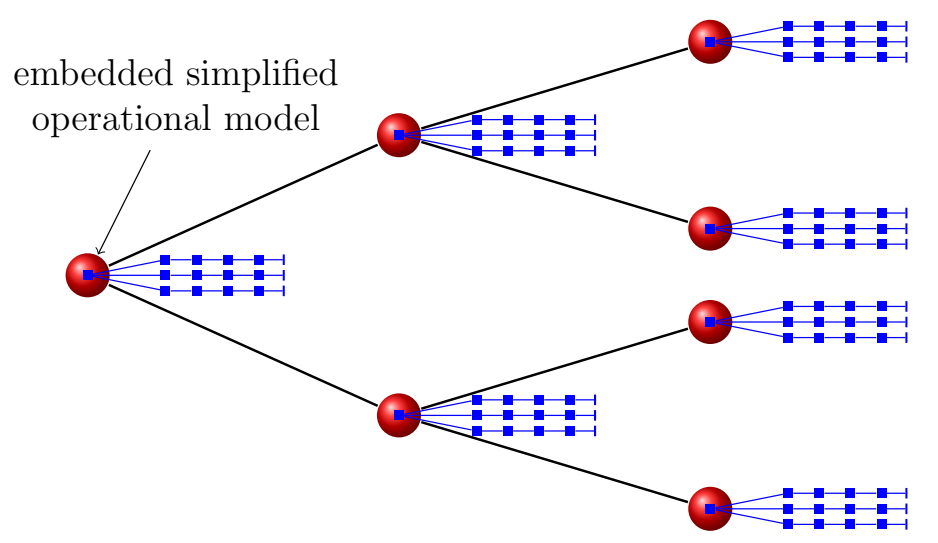

Figure 2: Multi-Horizon Scenario Tree Illustration

by modes of operation and seasonal conditions. However, accounting for both long-term uncertainties, e.g., in energy prices and technology costs, and short-term fluctuations, e.g., in weather and building occupancy, will render the resulting stochastic programming problem intractable as the number of scenarios expands exponentially with the number of decision-making stages. As a compromise, we use the multi-horizon scenario tree structure of Kaut et al. (2014b) depicted in Figure 2. The idea is to create a scenario tree for the strategic-decision nodes (represented by ' $\boldsymbol{\bullet}$ ' in the figure) and then attach to each of these nodes a set of seasonal profiles consisting of nodes with operational decisions (depicted as ' ''). From the modelling point of view, every strategic node includes an embedded operational model, most likely simplified to some degree, which is then solved for each of the operational nodes in all the attached profiles. In this way, the structure enables short-term operations of the installed equipment to influence strategic, e.g., investment, decisions, without running into the curse of dimensionality as the scenario tree branches only at the strategic nodes.

The rest of this paper is structured as follows:

- In Section 2, we describe the stochastic programming model for longterm planning in the context of buildings, which we, henceforth, refer to as strategic (optimisation) model.

- In Section 3, we run the model using data calibrated for two real buildings. We test the model under various regulatory proposals in order to gain policy insights.

- In Section 4, we discuss the implications of the results. 
- Finally, Section 5 summarises our findings, discusses the limitations of our approach, and offers directions for future research in this area.

\section{Methods}

In this section, we give a brief overview of the strategic optimisation model, which has been developed as a part of the EnRiMa project and has been already presented as a part of Deliverable D4.3 of the project (EnRiMa, 2013) and summarised in Cano et al. (2016). However, to keep the paper selfcontained, we present an abbreviated version ${ }^{1}$ of the model's mathematical formulation in Appendix A.

The building owner's decision-making problem is formulated as a multistage stochastic optimisation model. The model determines the optimal policy for investment in new technologies and decommissioning of old equipment, given that the building's energy demands must be met uninterruptedly over the planning horizon. Thus, along with strategic decision variables and constraints on investments, the model comprises operational decision variables and constraints that deal with energy production, storage, and procurement in order to evaluate the performance of the strategic decisions (as shown in Figure 2). The planning horizon is partitioned into strategic (long-term) decision periods (e.g., with yearly time resolution), each of which accommodates many operational (short-term) decision periods (e.g., with hourly time resolution). Strategic decisions are selected at the start of each strategic period, whereas operational decisions are made during each operational period. To reduce computational complexity, we assume that strategic periods can be described by a small set of operational profiles (with assigned probabilities). For instance, the operational profiles can be a selection of typical days representing conditions during different seasons and load periods and of extreme days with particularly high load. Operational decision variables and constraints for every operational period (e.g., hour) of each of these days are included in the model.

Concretely, the constraints of the model can be divided into the following categories:

\footnotetext{
${ }^{1}$ The full version of the strategic optimisation model considers a mean-risk objective function of either the discounted cost, the $\mathrm{CO}_{2}$ emissions, or the primary energy consumption. For the sake of brevity, some constraints that were irrelevant for the purpose of this paper were left out from Appendix A.
} 


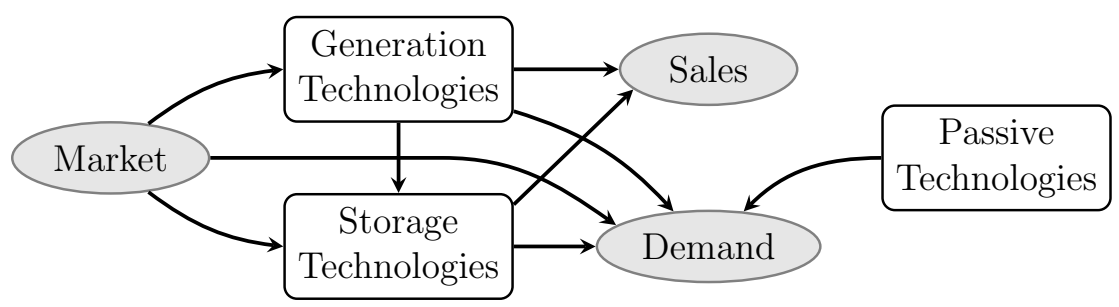

Figure 3: Energy Flow Diagram

Strategic constraints deal with strategic decisions, such as investments and contracting. These constraints keep track of the installed equipment, impose upper limits on the number of installed devices, and guarantee that only one sales and purchasing tariff is chosen per node and energy type.

Operational constraints deal with operational decisions, such as energy trade, generation, or storage. These include the energy-balance equations in each time period, ${ }^{2}$ schematically illustrated in Figure 3. The net energy supply consists of the energy produced by energy-generating technologies plus the energy discharged from storage and the energy purchases less the energy used for production or charging of storage devices and the energy sold. Also part of this constraint category are the storage balance equations, which keep an inventory of the energy available in energystorage equipment.

Strategic-operational constraints link the operational performance with the strategic decisions or policies. These constraints ensure that the technologies operate within the installed capacity limits and according to their availability (e.g., photovoltaic panels cannot produce electric energy during the night) and that the energy purchases and sales do not exceed the volumes stipulated in the signed energy contracts. Moreover, they guarantee that the energy charged, discharged, and stored into energy-storage devices remains within certain limits dictated by the infrastructure and chemistry of those devices.

Performance constraints quantify and impose a cap on primary energy consumption, pollution emissions, costs, and risk exposure (measured by

\footnotetext{
${ }^{2}$ Specifically, they guarantee that, for each energy type, the net energy supply must meet the energy demand (less the energy saved due to passive technologies).
} 
the CVaR).

In our strategic optimisation model, we consider a mean-risk objective function of the total discounted cost, which is composed of the discounted installation, decommissioning, maintenance, energy trading, and technology operation costs. Thus, the goal is to minimise a weighted average of the expected value and the CVaR of the total discounted costs.

\section{Results}

In order to provide managerial and policy insights about capacity expansion under uncertainty at public buildings, we implement the strategic optimisation model using data from two real EU buildings. The first is Centro de Adultos La Arboleya (Siero, Spain, 43.38 $\mathrm{N}, 5.65^{\circ} \mathrm{W}$ ), which belongs to the Fundación Asturiana de Atención y Protección a Personas con Discapacidades y/o Dependencias (FASAD). The second site is Fachhochschule Burgenland's Pinkafeld campus, which is located in Pinkafeld, Austria (47.37 $\mathrm{N}, 16.12^{\circ} \mathrm{E}$ ). For our numerical experiments, we consider a planning horizon of sixteen years with yearly strategic and hourly operational decision intervals. For FASAD, monthly operational profiles are used, whereas one operational profile is created for each month-weekday/weekend combination for Pinkafeld. Discounting is carried out at an annual rate of $3 \%$. We have previously presented results with $5 \%$ discount rates for the same two sites (EnRiMa, 2014). While the numerical results differ due to changes in the calibrating parameters, the qualitative insights are similar to those obtained in our work.

We represent uncertainty in energy prices, technology investment costs, and energy demands in the strategic model by approximating the distribution of these random parameters by a discretisation in the form of a multi-horizon scenario tree (Kaut et al., 2014a) that branches at stages 5, 9, and 13 and has a branching factor of 4, thereby resulting in a total of 64 scenarios. Assuming that the random parameters follow a normal distribution, scenario values are constructed using the copula-based approach from Kaut (2014). Historical data are used to estimate the parameters of the distribution of the energy prices; see Tables 9 and 13 for FASAD's and Pinkafeld's parameters, respectively.

For each test site, we run the model with all investment and decommissioning decisions first fixed ("do nothing" situation, N) and then enabled 
("invest" case, I). In addition, we investigate the impact of various regulatory settings (determined in consultation with local experts) on the optimal investment solutions. For FASAD, these are the following:

Setting S1 (baseline): flat energy tariff rates $\left(0.1426 € / \mathrm{kWh}_{e}\right.$ for electricity purchases and $0.0523 € / \mathrm{kWh}$ for natural gas purchases); electricity $\mathrm{FiT}^{3}$ for combined heat and power $(\mathrm{CHP})$ of $0.1721 € / \mathrm{kWh}_{e}$.

Setting S1s: same as setting $\mathrm{S} 1$ but with thermal storage.

Setting S2: revocation of the FiT for CHP.

Setting S3: a regulatory requirement that the primary energy consumption be reduced by $30 \%$ relative to the "do nothing" situation.

Setting S4: modernisation of the lighting equipment (by replacing the building's T8/TLD fluorescent lights with electromagnetic ballast with T5 fluorescent lights with electronic ballast).

For Pinkafeld, we examine the following settings:

Setting S1 (baseline): flat energy tariff rates $\left(0.15 € / \mathrm{kWh}_{e}\right.$ for electricity purchases, $0.08 € / \mathrm{kWh}_{e}$ for electricity sales, and $0.08 € / \mathrm{kWh}$ for district heat purchases).

Setting S1s: same as setting S1 but with thermal storage.

Setting S2: availability of a subsidy of $200 € / \mathrm{kW}_{p}$ and a FiT for new PV installations ${ }^{4}$ (with a rate of $0.125 € / \mathrm{kWh}_{e}$ ).

Setting S3: regulatory requirement that imposes $30 \%$ savings in primary energy consumption relative to the "do nothing" situation.

Setting S4: change from a flat to a time-of-use (ToU) electricity purchasing tariff ${ }^{5}$ (whose rate is $0.16 € / \mathrm{kWh}_{e}$ between 7:00 and 14:00 and between 17:00 and 20:00, 0.15 $€ / \mathrm{kWh}_{e}$ between 14:00 and 17:00, and 0.14 $€ / \mathrm{kWh}_{e}$ otherwise).

Likewise, we also consulted with local experts to determine plausible investment options. For FASAD, the technologies under consideration are the

\footnotetext{
${ }^{3}$ Source: Special Scheme for Electricity Generation with Renewable Energy Sources (BOE, 2013).

${ }^{4}$ Source: Ökostrom-Einspeisetarifverordnung 2012 (BKA, 2013).

${ }^{5}$ Source: Gewerbestrom SMART tariff of Energie AG (http://www.energieag.at/) from May 2013. The tariff has been adjusted so that its average hourly rate is equal to the corresponding flat rate of the baseline setting.
} 
following:

Currently installed: one $1279.1 \mathrm{~kW}$ and one $232.6 \mathrm{~kW}$ natural gasfired boiler, and one $5.5 \mathrm{~kW}_{e}$ CHP unit.

Investment options: $5.5 \mathrm{~kW}_{e} \mathrm{CHP}$ units, $0.245 \mathrm{~kW}_{p} \mathrm{PV}$ panels, and $2.011 \mathrm{~kW}$ solar thermal (ST) collectors.

For Pinkafeld, the following equipment is considered:

Currently installed: one $1.28 \mathrm{~kW}_{p}$ PV system and one $79.8 \mathrm{~kW}$ HVAC system.

Investment options: $1.28 \mathrm{~kW}_{p} \mathrm{PV}$ panels and $1 \mathrm{~kW}$ ST collectors.

The main input parameters used in our numerical experiments are presented in Appendix B. ${ }^{6}$ The strategic model is implemented as a mixedinteger linear program in the General Algebraic Modeling System (GAMS) and solved using GUROBI on a $2 \mathrm{GHz}$ Intel Core i7 laptop with $8 \mathrm{~GB}$ of RAM in under 45 minutes.

\subsection{FASAD}

The numerical results for FASAD with expected cost minimisation exhibit significant benefits relative to the "do nothing" situation (Table 1), which has an expected discounted cost over 16 years of $€ 3.7$ million. Using an optimal retrofitting strategy as in setting $\mathrm{S} 1$, this expected cost may be trimmed by $€ 0.3$ million. By investing in PV and ST technologies, it is possible to reduce the expected discounted cost by $8.5 \%$ with approximately $20 \%$ savings in expected primary energy consumption and $\mathrm{CO}_{2}$ emissions. Even the risk, measured by the CVaR of the discounted total costs, is reduced by nearly $10 \%$. This means that the expected discounted cost of the $5 \%$ worst scenarios is $€ 3.9$ million with the strategic model as opposed to nearly $€ 4.4$ million without it. Intuitively, by investing in on-site technologies (such as PV and ST) and operating them optimally, the building owner reduces the CVaR because these technologies are used especially when energy prices are high. Thus, although their adoption involves capital expenditure, their relatively

\footnotetext{
${ }^{6}$ Prior to implementing the examples, we first calibrate our model by running it for the current year only with all strategic variables fixed. The resulting output, e.g., energy consumption, production, purchases, and sales, matches the observed values. Next, we generate scenarios for energy prices, technology costs, and energy demand over the specified time horizon. We use both time-series data and expert opinion to set suitable parameter values.
} 
low operating costs and high payoffs during precisely the "worst" scenarios mean that they are also able to reduce the building owner's risk. These findings are robust across most regulatory settings with further gains possible with the use of thermal storage (setting S1s) or replacement of lighting (setting S4), whereas revocation of the FiT (setting S2) makes only a modest difference.

The main exception arises in setting S3 in which primary energy consumption must be reduced by $30 \%$ relative to the "do nothing" case. While the required reduction in energy consumption is attainable, viz., by investing in larger PV and ST systems along with adopting $11 \mathrm{~kW}_{e}$ of $\mathrm{CHP}$, the lower savings in expected discounted cost and risk exposure vis-à-vis setting S1 may not be justifiable for the building owner. At FASAD, there does not seem to be a negative economic impact even in setting S3 as the site is able to reduce its expected cost slightly. However, for Pinkafeld (as we shall observe in the next section), the imposition of a $30 \%$ reduction in primary energy consumption may lead to an increase in expected cost. Without adequate compensation, policymakers may encounter resistance from the building sector in mandating such ambitious restrictions on energy consumption. Towards this end, the provision of better operational decision support to handle the greater complexities of running a CHP system or deploying thermal storage may mitigate the higher costs of more energy-efficient systems. Consequently, the regulatory framework would have to be extended to facilitate the integration of such enhanced building energy management systems (BEMS).

Besides minimising expected costs, other objectives may also be considered. For example, in Table 2, a risk-averse building owner's decision-making problem is solved by minimising the $95 \% \mathrm{CVaR}$ of the discounted cost. Although the risk (CVaR) is slightly lowered as a result of investment, this gain comes at a relatively high discounted expected cost, for all the studied settings. Specifically, in setting S1, the CVaR improves by $0.2 \%$, while the cost increases by $7.7 \%$ compared to the cost-minimisation case. The risk reduction is achieved by a greater emphasis on $\mathrm{CHP}$ and larger renewable energy systems.

Note that the two presented cases (expected-cost- and risk-minimisation) can be viewed as two extremes, whereby the model can be easily adjusted to optimise any linear combination of the two, thereby achieving strategy in line with the building manager's risk attitude. 
Table 1: Summary of Results for FASAD: Expected Cost Minimisation Framework

\begin{tabular}{|c|c|c|c|c|c|c|}
\hline case, setting & $\mathrm{N}, \mathrm{S} 1$ & I, S1 & $\mathrm{I}, \mathrm{S} 1 \mathrm{~s}$ & $\mathrm{I}, \mathrm{S} 2$ & I, S3 & $\mathrm{I}, \mathrm{S} 4$ \\
\hline \multicolumn{7}{|c|}{ average technology investment } \\
\hline $\begin{array}{l}\mathrm{CHP}\left(\mathrm{kW}_{e}\right) \\
\mathrm{PV}\left(\mathrm{kW}_{p}\right) \\
\mathrm{ST}(\mathrm{kW}) \\
\text { thermal storage }(\mathrm{kWh}) \\
\text { replace lighting }\end{array}$ & & $\begin{array}{c}87.2 \\
431.5\end{array}$ & $\begin{array}{c}87.7 \\
467.9 \\
129.5\end{array}$ & $\begin{array}{c}77.1 \\
426.0\end{array}$ & $\begin{array}{c}11.0 \\
110.0 \\
1046.7\end{array}$ & $\begin{array}{c}76.7 \\
433.0 \\
\text { Yes }\end{array}$ \\
\hline \multicolumn{7}{|c|}{ expected discounted cost } \\
\hline $\begin{array}{l}\text { cost }(\mathrm{k} €) \\
\% \text { savings }\end{array}$ & 3,689 & $\begin{array}{l}3,376 \\
8.5 \%\end{array}$ & $\begin{array}{l}3,363 \\
8.8 \%\end{array}$ & $\begin{array}{l}3,394 \\
8.0 \%\end{array}$ & $\begin{array}{l}3,535 \\
4.2 \%\end{array}$ & $\begin{array}{l}3,316 \\
10.1 \%\end{array}$ \\
\hline \multicolumn{7}{|c|}{ expected primary energy consumption } \\
\hline $\begin{array}{l}\text { energy consumed (MWh) } \\
\% \text { savings }\end{array}$ & 41,805 & $\begin{array}{l}33,462 \\
20.0 \%\end{array}$ & $\begin{array}{l}32,877 \\
21.4 \%\end{array}$ & $\begin{array}{l}33,515 \\
19.8 \%\end{array}$ & $\begin{array}{l}29,263 \\
30.0 \%\end{array}$ & $\begin{array}{l}32,899 \\
21.3 \%\end{array}$ \\
\hline \multicolumn{7}{|c|}{ expected $\mathrm{CO}_{2}$ emissions } \\
\hline $\begin{array}{l}\text { emissions (ton) } \\
\% \text { savings }\end{array}$ & 6,584 & $\begin{array}{l}5,064 \\
23.1 \%\end{array}$ & $\begin{array}{l}4,957 \\
24.7 \%\end{array}$ & $\begin{array}{l}5,074 \\
22.9 \%\end{array}$ & $\begin{array}{l}4,299 \\
34.7 \%\end{array}$ & $\begin{array}{l}4,963 \\
24.6 \%\end{array}$ \\
\hline \multicolumn{7}{|c|}{ risk } \\
\hline $\begin{array}{l}95 \% \text { CVaR }(\mathrm{k} €) \\
\% \text { savings }\end{array}$ & 4,370 & $\begin{array}{l}3,955 \\
9.5 \%\end{array}$ & $\begin{array}{c}3,927 \\
10.1 \%\end{array}$ & $\begin{array}{l}3,973 \\
9.1 \%\end{array}$ & $\begin{array}{l}4,064 \\
7.0 \%\end{array}$ & $\begin{array}{l}3,896 \\
10.8 \%\end{array}$ \\
\hline
\end{tabular}


Table 2: Summary of Results for FASAD: Risk Minimisation Framework

\begin{tabular}{|c|c|c|c|c|c|c|}
\hline case, setting & $\mathrm{N}, \mathrm{S} 1$ & $\mathrm{I}, \mathrm{S} 1$ & I, S1s & $\mathrm{I}, \mathrm{S} 2$ & $\mathrm{I}, \mathrm{S} 3$ & I, S4 \\
\hline \multicolumn{7}{|c|}{ average technology investment } \\
\hline $\mathrm{CHP}\left(\mathrm{kW}_{e}\right)$ & & 15.1 & 18.4 & 18.4 & 15.2 & 15.1 \\
\hline $\mathrm{PV}\left(\mathrm{kW}_{p}\right)$ & & 123.5 & 102.5 & 107.7 & 149.6 & 76.7 \\
\hline $\mathrm{ST}(\mathrm{kW})$ & & 655.9 & 737.1 & 643.5 & 1559.1 & 637.9 \\
\hline thermal storage $(\mathrm{kWh})$ & & & 557.3 & & & \\
\hline replace lighting & & & & & & Yes \\
\hline \multicolumn{7}{|c|}{ expected discounted cost } \\
\hline $\operatorname{cost}(k €)$ & 3,689 & 3,635 & 3,587 & 3,612 & 3,831 & 3,562 \\
\hline$\%$ savings & & $1.5 \%$ & $2.8 \%$ & $2.1 \%$ & $-3.9 \%$ & $3.4 \%$ \\
\hline \multicolumn{7}{|c|}{ expected primary energy consumption } \\
\hline energy consumed (MWh) & 41,805 & 33,094 & 31,397 & 32,784 & 29,263 & 32,305 \\
\hline$\%$ savings & & $20.8 \%$ & $24.9 \%$ & $21.6 \%$ & $30.0 \%$ & $22.7 \%$ \\
\hline \multicolumn{7}{|c|}{ expected $\mathrm{CO}_{2}$ emissions } \\
\hline emissions (ton) & 6,584 & 4,993 & 4,682 & 4,937 & 4,298 & 4,849 \\
\hline$\%$ savings & & $24.2 \%$ & $28.9 \%$ & $25.0 \%$ & $34.7 \%$ & $26.4 \%$ \\
\hline \multicolumn{7}{|c|}{ risk } \\
\hline 95\% CVaR $(\mathrm{k} €)$ & 4,370 & 3,946 & 3,907 & 3,964 & 3,950 & 3,888 \\
\hline$\%$ savings & & $9.7 \%$ & $10.6 \%$ & $9.3 \%$ & $9.6 \%$ & $11.0 \%$ \\
\hline
\end{tabular}




\subsection{Pinkafeld}

For Pinkafeld, the site's more recent refurbishment along with the relatively low levels of $\mathrm{CO}_{2}$ emissions from district heating and power mean that the building is in a good position from a sustainability perspective. In particular, compare the expected $\mathrm{CO}_{2}$ emissions of 239 tons in Table 3 for the "do nothing" situation with the corresponding one for FASAD in Table 1 (6584 tons). Nevertheless, as Tables 3-4 illustrate, improvements to the current configuration are still possible. For example, the installation of PV panels and ST collectors can reduce expected primary energy consumption and $\mathrm{CO}_{2}$ emissions by $18.4 \%$ and $24.5 \%$, respectively, along with more modest reductions in expected cost and risk. As with FASAD, the imposition of requirements to reduce primary energy consumption (setting S3) may pose a challenge for building owners. In fact, for Pinkafeld, the expected cost would increase by $30 \%$ above the current values because of already-high energy efficiency.

Table 3: Summary of Results for Pinkafeld: Expected Cost Minimisation Framework

\begin{tabular}{|c|c|c|c|c|c|c|}
\hline case, setting & N, S1 & $\mathrm{I}, \mathrm{S} 1$ & $\mathrm{I}, \mathrm{S} 1 \mathrm{~s}$ & I, S2 & I, S3 & $\mathrm{I}, \mathrm{S} 4$ \\
\hline \multicolumn{7}{|c|}{ average technology investment } \\
\hline $\mathrm{PV}\left(\mathrm{kW}_{p}\right)$ & & 108.8 & 108.8 & 165.1 & 352.0 & 111.4 \\
\hline $\mathrm{ST}(\mathrm{kW})$ & & 17.5 & 73.0 & 17.5 & 548.7 & 17.5 \\
\hline thermal storage $(\mathrm{kWh})$ & & & 192.1 & & & \\
\hline \multicolumn{7}{|c|}{ expected discounted cost } \\
\hline $\operatorname{cost}(\mathrm{k} €)$ & 1,079 & 990 & 962 & 953 & 1,402 & 990 \\
\hline$\%$ savings & & $8.2 \%$ & $10.8 \%$ & $11.6 \%$ & $-30.0 \%$ & $8.2 \%$ \\
\hline \multicolumn{7}{|c|}{ expected primary energy consumption } \\
\hline energy consumed (MWh) & 12,009 & 9,804 & 8,311 & 9,408 & 8,406 & 9,776 \\
\hline$\%$ savings & & $18.4 \%$ & $30.8 \%$ & $21.7 \%$ & $30.0 \%$ & $18.6 \%$ \\
\hline \multicolumn{7}{|c|}{ expected $\mathrm{CO}_{2}$ emissions } \\
\hline emissions (ton) & 239 & 181 & 158 & 170 & 150 & 180 \\
\hline$\%$ savings & & $24.5 \%$ & $33.9 \%$ & $29.1 \%$ & $37.2 \%$ & $24.8 \%$ \\
\hline \multicolumn{7}{|c|}{ risk } \\
\hline 95\% CVaR (k€) & 1,285 & 1,120 & 1,087 & 1,068 & 1,500 & 1,115 \\
\hline$\%$ savings & & $12.8 \%$ & $15.4 \%$ & $16.9 \%$ & $-16.7 \%$ & $13.2 \%$ \\
\hline
\end{tabular}

Elsewhere, the patterns of the results are broadly similar to those for FASAD: the availability of storage (setting S1s) enhances the expected primary energy savings, while offering a FiT for PV with a subsidy (setting S2) 
or switching to a ToU tariff (setting S4) modestly improves the metrics. Finally, using other objective functions, e.g., minimisation of risk, implies that larger PV or ST systems are required at the expense of slightly higher expected discounted costs. As with FASAD, the purpose of using a mean-risk framework is to identify cases in which risk aversion would affect technology choice. Here, greater investment in all candidate technologies would be required to achieve the desired risk minimisation.

Table 4: Summary of Results for Pinkafeld: Risk Minimisation Framework

\begin{tabular}{|c|c|c|c|c|c|c|}
\hline case, setting & N, S1 & $\mathrm{I}, \mathrm{S} 1$ & $\mathrm{I}, \mathrm{S} 1 \mathrm{~s}$ & $\mathrm{I}, \mathrm{S} 2$ & I, S3 & $\mathrm{I}, \mathrm{S} 4$ \\
\hline \multicolumn{7}{|c|}{ average technology investment } \\
\hline $\mathrm{PV}\left(\mathrm{kW}_{p}\right)$ & & 187.3 & 127.1 & 222.3 & 349.6 & 148.5 \\
\hline $\mathrm{ST}(\mathrm{kW})$ & & 52.0 & 114.3 & 41.8 & 683.6 & 51.4 \\
\hline thermal storage $(\mathrm{kWh})$ & & & 283.7 & & & \\
\hline \multicolumn{7}{|c|}{ expected discounted cost } \\
\hline $\operatorname{cost}(\mathrm{k} €)$ & 1,079 & 1,093 & 1,053 & 1,046 & 1,432 & 1,083 \\
\hline$\%$ savings & & $-1.3 \%$ & $2.4 \%$ & $3.0 \%$ & $-32.8 \%$ & $-0.4 \%$ \\
\hline \multicolumn{7}{|c|}{ expected primary energy consumption } \\
\hline energy consumed (MWh) & 12,009 & 9,598 & 8,793 & 9,459 & 8,406 & 9,795 \\
\hline$\%$ savings & & $20.1 \%$ & $26.8 \%$ & $21.2 \%$ & $30.0 \%$ & $18.4 \%$ \\
\hline \multicolumn{7}{|c|}{ expected $\mathrm{CO}_{2}$ emissions } \\
\hline emissions (ton) & 239 & 175 & 167 & 171 & 150 & 181 \\
\hline$\%$ savings & & $26.6 \%$ & $30.2 \%$ & $28.3 \%$ & $37.2 \%$ & $24.4 \%$ \\
\hline \multicolumn{7}{|c|}{ risk } \\
\hline $95 \% \mathrm{CVaR}(\mathrm{k} €)$ & 1,285 & 1,117 & 1,083 & 1,064 & 1,434 & 1,112 \\
\hline$\%$ savings & & $13.0 \%$ & $15.7 \%$ & $17.2 \%$ & $-11.6 \%$ & $13.4 \%$ \\
\hline
\end{tabular}

\section{Discussion}

Cano et al. (2014) have presented an approach analogous to the one of this paper and validated it with data from a real building but under the assumption of deterministic energy prices and technology costs. Here, we extend the approach to a stochastic model with the objective of performing detailed case studies using data from two real buildings, in the EU in order to extract policy insights. Towards that end, we implement our stochastic programming model for a 16-year planning horizon using scenarios generated to reflect the future evolution of energy prices, technology costs, and building 
energy demands. We calibrate parameters for each site to reflect the current energy balances and run the model under various regulatory proposals with the objective of either minimising the expected cost or the CVaR. Relative to the "do nothing" situation of maintaining the existing building configuration, the two sites benefit from substantial savings in primary energy consumption, approximately 20\%, with similar levels of reduction in expected $\mathrm{CO}_{2}$ emissions.

In terms of policy insights, we find that while more stringent energyefficiency requirements are economical, they, nevertheless, may not be desirable as building owners could face higher expected costs or greater risk exposure. Effectively, such a regulatory proposal will require a higher installed capacity of CHP equipment, which will necessitate more sophisticated operational decision support for building managers. Thus, the enhancement of existing BEMS to accommodate more complex decisions, e.g., considering the complementarities between electricity and heating loads, would be a tangible step for policymakers to support.

\section{Conclusions and Policy Implications}

Current and forthcoming EU directives will require compliance with energyefficiency measures. For example, after 2020, public buildings are supposed to become nearly zero energy. Thus, existing building owners face the challenge of deciding which technologies to adopt in the long term. Confounding their task are not only the manifold choices but also the uncertainty in energy prices and technology costs. Hence, addressing the building owner's attitude to risk is a crucial element of strategic decision support.

Given this background, we implement a stochastic model for analysing strategic decision making at the building level. Using two EU test sites, we calibrate parameters to be able to replicate their observed energy balances. Next, we generate scenarios for uncertain parameters over which we solve the resulting problem. We find that relative to the "do nothing" situation, the two sites are able to benefit from substantial savings in expected primary energy consumption with similar levels of expected $\mathrm{CO}_{2}$ emissions reductions. These are accompanied by more modest improvements in economic and financial indicators. Finally, we are also able to investigate the effects of alternative regulatory settings and objective functions.

The main policy insight from this analysis is that deeper reductions in energy consumption may be possible at the building level via careful retrofitting 
decisions. Although changing tariffs may have a modest influence, we find that more stringent restrictions, such as the ones proposed for post-2020, will have a stronger impact. Nevertheless, such mandates may result in limited economic benefit or even losses for building owners, which may need to be addressed via further regulatory dispensations. In particular, both test buildings rely more heavily on DER in order to meet stricter energy efficiency requirements. Without more sophisticated decision support, e.g., in the form of "smart" BEMS that can proactively deploy resources and control demand in response to fluctuating conditions, it would be difficult for building owners to integrate such technologies, especially CHP, because of the added complexity of managing electricity and heat demands simultaneously. Hence, a tangible measure that policymakers can take is to require manufacturers of BEMS to provide such capacity for enhanced decision support or to facilitate integration of their software with vendors of middleware.

\section{Acknowledgements}

The research leading to these results has received funding from the European Union Seventh Framework Programme under grant agreement no. 260041 for Collaborative Project "Energy Efficiency and Risk Management in Public Buildings" (EnRiMa). We are grateful to our EnRiMa partners Universidad Rey Juan Carlos, Stockholm University, SINTEF, Center for Energy and Innovative Technologies (CET), Hidrocantábrico Energía, and Tecnalia Research and Innovation for their valuable input. Feedback from anonymous referees has helped to improve this paper. All remaining errors are the authors' own.

\section{References}

Ashouri, A., Fux, S., Benz, M., and Guzzella, L. (2013). Optimal Design and Operation of Building Services using Mixed-Integer Linear Programming Techniques. Energy, 59:365-376.

Birge, J. and Louveaux, F. (1997). Introduction to Stochastic Programming. Springer.

BKA (2013). Änderung der Ökostrom-Einspeisetarifverordnung 2012. Green Energy Regulation ÖSET-VO 2012, Bundeskanzleramt Österreich. 
BOE (2013). Orden IET/1491/2013, de 1 de Agosto, por la que se Revisan los Peajes de Acceso de Energía Eléctrica para su Aplicación a partir de Agosto de 2013 y por la que se Revisan Determinadas Tarifas y Primas de las Instalaciones del Régimen Especial para el Segundo Trimestre de 2013. Special Scheme for Electricity Generation with Renewable Energy Sources BOE-A-2013-8561, Agencia Estatal Boletín Oficial del Estado.

Cano, E. L., Groissböck, M., Moguerza, J. M., and Stadler, M. (2014). A Strategic Optimization Model for Energy Systems Planning. Energy and Buildings, 81:416-423.

Cano, E. L., Moguerza, J. M., and Alonso-Ayuso, A. (2016). A multi-stage stochastic optimization model for energy systems planning and risk management. Energy and Buildings, 110:49-56.

Chen, Y. and Wang, L. (2013). Renewable Portfolio Standards in the Presence of Green Consumers and Emission Trading Programs. Networks and Spatial Economics, 13(2):149-181.

Conejo, A., Carrión, M., and Morales, J. (2010). Decision Making under Uncertainty in Electricity Markets. Springer, Heidelberg, Germany.

EC (2010). Directive 2010/31/EU of the European Parliament and of the Council of 19 May 2010 on the Energy Performance of Buildings. Technical report, European Commission.

EnRiMa (2013). Stochastic optimization prototype. Deliverable D4.3 of the EnRiMa project, available from http://enrima-project.eu/project/ publications.

EnRiMa (2014). Advisory report on the potential capacity expansion policy. Deliverable D7.3 of the EnRiMa project, available from http://www.homepages.ucl.ac.uk/ ucakasi/Research/ deliverable31032014.pdf.

Georgopoulou, E., Sarafidis, Y., Mirasgedis, S., Balaras, C., Gaglia, A., and Lalas, D. (2006). Evaluating the Need for Economic Support Policies in Promoting Greenhouse Gas Emission Reduction Measures in the Building Sector: The Case of Greece. Energy Policy, 34(15):2012-2031. 
Groissböck, M., Heydari, S., Mera, A., Perea, E., Siddiqui, A., and Stadler, M. (2014). Optimizing Building Energy Operations via Dynamic Zonal Temperature Settings. Journal of Energy Engineering, 140(1):1-10.

Kall, P. and Wallace, S. W. (1994). Stochastic Programming. John Wiley \& Sons, Chichester.

Kaut, M. (2014). A Copula-Based Heuristic for Scenario Generation. Computational Management Science, 11(4):503-516.

Kaut, M., Midthun, K., Werner, A., Tomasgard, A., Hellemo, L., and Fodstad, M. (2014a). Multi-Horizon Stochastic Programming. Computational Management Science, 11(1-2):179-193.

Kaut, M., Midthun, K. T., Werner, A. S., Tomasgard, A., Hellemo, L., and Fodstad, M. (2014b). Multi-horizon stochastic programming. Computational Management Science, 11(1-2):179-193. Special Issue: Computational Techniques in Management Science.

King, D. and Morgan, M. (2007). Adaptive-Focused Assessment of Electric Power Microgrids. Journal of Energy Engineering, 133(3):150-164.

Kumbaroğlu, G. and Madlener, R. (2012). Evaluation of Economically Optimal Retrofit Investment Options for Energy Savings in Buildings. Energy and Buildings, 49:327-334.

Liang, Y., Levine, D., and Shen, Z.-J. (2012). Thermostats for the SmartGrid: Models, Benchmarks, and Insights. The Energy Journal, 33(4):6196.

Maribu, K. and Fleten, S.-E. (2008). Combined Heat and Power in Commercial Buildings: Investment and Risk Analysis. The Energy Journal, 29(2):123-150.

Marnay, C., Venkataramanan, G., Stadler, M., Siddiqui, A., Firestone, R., and Chandran, B. (2008). Optimal Technology Selection and Operation of Commercial-Building Microgrids. IEEE Transactions on Power Systems, 23(3):975-982.

Omu, A., Choudhary, R., and Boies, A. (2013). Distributed Energy Resource System Optimisation Using Mixed Integer Linear Programming. Energy Policy, 61:249-266. 
Rockafellar, R. and Uryasev, S. (2000). Optimization of Conditional Valueat-Risk. Journal of Risk, 2:21-42.

Rockafellar, R. and Uryasev, S. (2002). Conditional Value-at-Risk for General Loss Distributions. Journal of Banking \& Finance, 26(7):1443-1471.

Siddiqui, A. and Maribu, K. (2009). Investment and Upgrade in Distributed Generation under Uncertainty. Energy Economics, 31(1):25-37.

Stadler, M., Siddiqui, A., Marnay, C., Aki, H., and Lai, J. (2011). Control of Greenhouse Gas Emissions by Optimal DER Technology Investment and Energy Management in Zero-Net-Energy Buildings. European Transactions on Electrical Power, 21(2):1291-1309.

Strbac, G. (2008). Demand Side Management: Benefits and Challenges. Energy Policy, 36(12):4419-4426.

von Hirschhausen, C. (2014). The German 'Energiewende' - An Introduction. Economics of Energy \& Environmental Policy, 3(2):1-12.

Wilson, R. (2002). Architecture of Power Markets. Econometrica, 70(4):1299-1340.

Woodman, B. and Mitchell, C. (2011). Learning from Experience? The Development of the Renewables Obligation in England and Wales 20022010. Energy Policy, 39(7):3914-3921.

\section{Appendix A Model Formulation}

In this appendix, we present the mathematical formulation of the strategic optimisation model.

\section{A.1 Nomenclature}

A.1.1 Sets

$\mathcal{A} \quad$ Technology age.

$\mathcal{A}_{\text {Ages }}^{i, v} \quad$ Possible ages of technology $i \in \mathcal{I}$ at node $v \in \mathcal{V}$.

$\mathcal{A}_{\text {New }}:=\{0\} \subset \mathcal{A} \quad$ Zero age.

$\mathcal{A}_{\text {Old }}:=\mathcal{A} \backslash\{0\} \subset \mathcal{A} \quad$ Non-zero age. 
Energy technology.

$\mathcal{I}_{\text {Gen }} \subset \mathcal{I}$

Energy-generation technologies.

$\mathcal{I}_{\text {Inv }} \subset \mathcal{I}$

Technologies available for investment.

$\mathcal{I}_{P U} \subset \mathcal{I}$

Passive technologies (unitary).

$\mathcal{I}_{\text {Sto }} \subset \mathcal{I}$

Energy-storage technologies.

$\mathcal{K}$

Energy type.

$\mathcal{K}_{\text {Epur }} \subset \mathcal{K}$

Types of energy which can be purchased.

$\mathcal{K}_{E S} \subset \mathcal{K}$

Types of energy which can be sold.

$\mathcal{K}_{I n}^{i} \subset \mathcal{K}$

Input energy types for technology $i \in \mathcal{I}_{\text {Gen }}$.

$\mathcal{K}_{\text {Out }}^{i} \subset \mathcal{K}$

Output energy types for technology $i \in \mathcal{I}_{\text {Gen }}$.

$\mathcal{K}_{P_{o}}^{i} \subset \mathcal{K}$

Principal output energy type for technology $i \in \mathcal{I}$.

$\mathcal{L}$

Type of pollutant.

lf $(s) \subset \mathcal{V}_{\text {Path }}^{s}$

$\mathcal{M}$

Leaf node of scenario $s \in \mathcal{S}$.

$\mathcal{N}$

Operational profile.

$\mathcal{N}_{\text {Pur }}^{k} \subset \mathcal{N}$

Energy tariff.

$\mathcal{N}_{\text {Sal }}^{k} \subset \mathcal{N}$

Purchase tariffs for energy type $k \in \mathcal{K}_{\text {Epur }}$.

$p a(v) \subset \mathcal{V}$

Sales tariffs for energy type $k \in \mathcal{K}_{E S}$.

$\mathcal{S}$

$\mathcal{T}$

$\mathcal{T}_{\text {First }}^{m} \subset \mathcal{T}_{\text {Tm }}^{m}$

Parent of node $v \in \mathcal{V}_{F u t}$.

Scenario.

Short-term (operational) period.

$\mathcal{T}_{\text {Last }}^{m} \subset \mathcal{T}_{\text {Tm }}^{m}$

First short-term period in profile $m \in \mathcal{M}$.

$\mathcal{T}_{T m}^{m} \subset \mathcal{T}$

Last short-term period in profile $m \in \mathcal{M}$.

$\mathcal{V}$

Short-term periods in profile $m \in \mathcal{M}$.

Scenario tree nodes.

$\mathcal{V}_{\text {Fut }} \subset \mathcal{V}$

Non-root nodes.

$\mathcal{V}_{\text {Path }}^{s} \subset \mathcal{V}$

Nodes that scenario $s \in \mathcal{S}$ passes through.

$\mathcal{V}_{\text {Root }} \subset \mathcal{V}$

Root node.

A.1.2 Constants

$A L \in[0,1)$

Confidence level for the CVaR (-).

$B E \in[0,1]$

Risk weight (-). 


\section{A.1.3 Parameters}

$A F_{i}^{v, m, t}$ Availability factor of technology $i \in \mathcal{I}$ in period $t \in \mathcal{T}_{T m}^{m}$ of profile $m \in \mathcal{M}$ and node $v \in \mathcal{V}(-)$.

$A G_{i}^{a} \quad$ Ageing factor of technology $i \in \mathcal{I}$ for age $a \in \mathcal{A}(-)$.

$B_{k, n} \quad$ Units of primary energy required to produce one unit of energy $k \in \mathcal{K}_{\text {Epur }}$ purchased under tariff $n \in \mathcal{N}_{\text {Pur }}^{k}(-)$.

$C D_{i}^{v, a} \quad$ Decommissioning cost of technology $i \in \mathcal{I}$ aged $a \in \mathcal{A}_{\text {Ages }}^{i, v}$ at node $v \in \mathcal{V}(€ / \mathrm{kW}$ or $€ / \mathrm{kWh})$.

$C I_{i}^{v} \quad$ Installation cost of technology $i \in \mathcal{I}$ at node $v \in \mathcal{V}(€ / \mathrm{kW}$ or $€ / \mathrm{kWh})$.

$C M_{i}^{v} \quad$ Maintenance cost of technology $i \in \mathcal{I}$ at node $v \in \mathcal{V}(€ / \mathrm{kW}$ or $€ / \mathrm{kWh})$.

$C O_{i, k}^{v} \quad$ Operation cost of producing energy type $k \in \mathcal{K}_{\text {Out }}^{i}$ using technology $i \in \mathcal{I}_{G e n}$ at node $v \in \mathcal{V}(€ / \mathrm{kWh})$.

$D_{k}^{v, m, t} \quad$ Demand for energy type $k \in \mathcal{K}$ in period $t \in \mathcal{T}_{T m}^{m}$ of profile $m \in \mathcal{M}$ and node $v \in \mathcal{V}(\mathrm{kWh})$.

$D M^{m} \quad$ Weight of operational profile $m \in \mathcal{M}$ in a stage (days).

$D T^{m} \quad$ Duration of a short-term period within profile $m \in \mathcal{M}$ (hours).

$E C_{i, k, k^{\prime}}^{v}$ Amount of output energy $k^{\prime} \in \mathcal{K}_{\text {Out }}^{i}$ generated with technology $i \in \mathcal{I}_{\text {Gen }}$ from one unit of input energy $k \in \mathcal{K}_{\text {In }}^{i}$ at node $v \in \mathcal{V}(-)$.

$E L^{v} \quad$ Primary energy consumption limit at node $v \in \mathcal{V}(\mathrm{kWh})$.

$G_{i} \quad$ Capacity of technology $i \in \mathcal{I}$ (kW/Device).

$I L^{v} \quad$ Investment limit at node $v \in \mathcal{V}(€)$.

$L C_{k, \ell, n}^{v}$ Emissions of pollutant $\ell \in \mathcal{L}$ per unit of energy $k \in \mathcal{K}_{\text {Epur }}$ purchased under tariff $n \in \mathcal{N}_{P \text { ur }}^{k}$ at node $v \in \mathcal{V}(\mathrm{kg} / \mathrm{kWh})$.

$L H_{k, \ell}^{v} \quad$ Emissions of pollutant $\ell \in \mathcal{L}$ by generating technologies per unit of energy input $k \in \mathcal{K}$ at node $v \in \mathcal{V}(\mathrm{kg} / \mathrm{kWh})$. 
$L P_{i}^{v} \quad$ Physical installation limit of technology $i \in \mathcal{I}$ at node $v \in \mathcal{V}$ (Devices, $\mathrm{kW}$, or $\mathrm{kWh}$ ).

$M E_{k, n} \quad$ Maximum purchase/sale of energy type $k \in \mathcal{K}$ under contract $n \in$ $\mathcal{N}_{\text {Pur }}^{k} \cup \mathcal{N}_{\text {Sal }}^{k}(\mathrm{~kW})$.

$O A_{i, k}^{v} \quad$ Fraction of the storage capacity of technology $i \in \mathcal{I}_{\text {Sto }}$ below which the level of stored energy of type $k \in \mathcal{K}_{P o}^{i}$ may not fall at node $v \in \mathcal{V}(-)$.

$O B_{i, k}^{v} \quad$ Fraction of the storage capacity of technology $i \in \mathcal{I}_{\text {Sto }}$ which the level of stored energy of type $k \in \mathcal{K}_{P o}^{i}$ may not exceed at node $v \in \mathcal{V}(-)$.

$O D_{i, k}^{v} \quad$ Reduction of demand for energy type $k \in \mathcal{K}_{P o}^{i}$ due to passive technology $i \in \mathcal{I}_{P U}$ at node $v \in \mathcal{V}(-)$.

$O I_{i, k}^{v} \quad$ Units of energy of type $k \in \mathcal{K}_{P o}^{i}$ available for each unit charged into energy-storage technology $i \in \mathcal{I}_{\text {Sto }}$ at node $v \in \mathcal{V}(-)$.

$O O_{i, k}^{v} \quad$ Units of energy of type $k \in \mathcal{K}_{\text {Po }}^{i}$ needed to be discharged from technology $i \in \mathcal{I}_{\text {Sto }}$ in order to obtain one unit of energy at node $v \in \mathcal{V}(-)$.

$O S_{i, k} \quad$ Amount of energy of type $k \in \mathcal{K}_{P o}^{i}$ available after one short-term period in technology $i \in \mathcal{I}_{\text {Sto }}$ per unit of energy stored $(-)$.

$O X_{i, k}^{v} \quad$ Maximum discharge rate of energy type $k \in \mathcal{K}_{P o}^{i}$ per unit of storage capacity of technology $i \in \mathcal{I}_{\text {Sto }}$ at node $v \in \mathcal{V}(\mathrm{kW} / \mathrm{kWh})$.

$O Y_{i, k}^{v} \quad$ Maximum charge rate of energy type $k \in \mathcal{K}_{P o}^{i}$ per unit of storage capacity of technology $i \in \mathcal{I}_{\text {Sto }}$ at node $v \in \mathcal{V}(\mathrm{kW} / \mathrm{kWh})$.

$P L_{\ell}^{v} \quad$ Limit on emissions of pollutant $\ell \in \mathcal{L}$ at node $v \in \mathcal{V}(\mathrm{kg})$.

$P P_{k, n}^{v, m, t} \quad$ Purchasing price of energy type $k \in \mathcal{K}_{\text {Epur }}$ under contract $n \in \mathcal{N}_{\text {Pur }}^{k}$ in period $t \in \mathcal{T}_{T m}^{m}$ of profile $m \in \mathcal{M}$ and node $v \in \mathcal{V}(€ / \mathrm{kWh})$.

$P R^{v} \quad$ Probability of node $v \in \mathcal{V}(-)$.

$P T^{v} \quad$ Time until the stage of node $v \in \mathcal{V}$ (years). 
$S P_{k, n}^{v, m, t}$ Sales price of energy type $k \in \mathcal{K}_{E S}$ under contract $n \in \mathcal{N}_{\text {Sal }}^{k}$ in period $t \in \mathcal{T}_{T m}^{m}$ of profile $m \in \mathcal{M}$ and node $v \in \mathcal{V}(€ / \mathrm{kWh})$.

$S U_{i}^{v} \quad$ Subsidies for investment in technology $i \in \mathcal{I}$ at node $v \in \mathcal{V}(€ / \mathrm{kW})$.

$X Z_{i}^{a} \quad$ Existing units of technology $i \in \mathcal{I}$ aged $a \in \mathcal{A}$ at the start of the optimisation horizon. (Devices, $\mathrm{kW}$, or $\mathrm{kWh}$ ).

\section{A.1.4 Decision Variables}

$c \quad$ Total expected discounted cost $(€)$.

$c n^{v} \quad$ Total discounted cost at node $v \in \mathcal{V}(€)$.

$e n^{v} \quad$ Primary energy consumed at node $v \in \mathcal{V}(\mathrm{kWh})$.

et Total expected energy consumption (kWh).

$h_{k, n}^{v} \quad$ Tariff choice for energy type $k \in \mathcal{K}$ and tariff $n \in \mathcal{N}_{\text {Pur }}^{k} \cup \mathcal{N}_{\text {Sal }}^{k}$ at node $v \in \mathcal{V}$ (binary).

$p \quad$ Total expected pollution emissions $(\mathrm{kg})$.

$p n_{\ell}^{v} \quad$ Total emissions of pollutant $\ell \in \mathcal{L}$ at node $v \in \mathcal{V}(\mathrm{kg})$.

$r_{i, k}^{v, m, t} \quad$ Amount of energy of type $k \in \mathcal{K}_{P o}^{i}$ that is stored in technology $i \in \mathcal{I}_{\text {Sto }}$ at the start of period $t \in \mathcal{T}_{T m}^{m}$ of profile $m \in \mathcal{M}$ and node $v \in \mathcal{V}(\mathrm{kWh})$.

$r i_{i, k}^{v, m, t} \quad$ Amount of energy of type $k \in \mathcal{K}_{P o}^{i}$ charged into technology $i \in \mathcal{I}_{\text {Sto }}$ during period $t \in \mathcal{T}_{T m}^{m}$ of profile $m \in \mathcal{M}$ and node $v \in \mathcal{V}(\mathrm{kWh})$.

$r o_{i, k}^{v, m, t} \quad$ Amount of energy of type $k \in \mathcal{K}_{P o}^{i}$ discharged from technology $i \in \mathcal{I}_{\text {Sto }}$ during period $t \in \mathcal{T}_{T m}^{m}$ of profile $m \in \mathcal{M}$ and node $v \in \mathcal{V}$ $(\mathrm{kWh})$.

rt Risk term, i.e., the CVaR at confidence level $A L(€)$.

$s r^{s} \quad$ Auxiliary variable for scenario $s \in \mathcal{S}$, to calculate the CVaR $(€)$.

$u_{k, n}^{v, m, t} \quad$ Amount of energy of type $k \in \mathcal{K}_{\text {Epur }}$ to purchase under tariff $n \in$ $\mathcal{N}_{\text {Pur }}^{k}$ in period $t \in \mathcal{T}_{T m}^{m}$ of profile $m \in \mathcal{M}$ and node $v \in \mathcal{V}(\mathrm{kWh})$.

vr $\quad$ VaR at confidence level $A L(€)$. 
$w_{k, n}^{v, m, t} \quad$ Amount of energy of type $k \in \mathcal{K}_{E S}$ to be sold under tariff $n \in \mathcal{N}_{\text {Sal }}^{k}$ in period $t \in \mathcal{T}_{T m}^{m}$ of profile $m \in \mathcal{M}$ and node $v \in \mathcal{V}(\mathrm{kWh})$.

$x_{i}^{v, a} \quad$ Installed units of technology $i \in \mathcal{I}$ and age $a \in \mathcal{A}_{\text {Aqes }}^{i, v}$ at node $v \in \mathcal{V}$ (Devices, $\mathrm{kW}$, or $\mathrm{kWh}$ ).

$x c_{i}^{v} \quad$ Available capacity of technology $i \in \mathcal{I}$ at node $v \in \mathcal{V}(\mathrm{kW}$ or $\mathrm{kWh})$.

$x d_{i}^{v, a} \quad$ Number of units of technology $i \in \mathcal{I}$ of age $\mathcal{A}_{\text {Old }} \cap \mathcal{A}_{\text {Ages }}^{i, v}$ to be decommissioned at node $v \in \mathcal{V}$ (Devices, $\mathrm{kW}$, or $\mathrm{kWh}$ ).

$x i_{i}^{v} \quad$ Number of units of technology $i \in \mathcal{I}$ to be installed at node $v \in \mathcal{V}$ (Devices, $\mathrm{kW}$, or $\mathrm{kWh}$ ).

$y_{i, k}^{v, m, t} \quad$ Amount of energy of type $k \in \mathcal{K}_{I n}^{i}$ used as input to technology $i \in \mathcal{I}_{\text {Gen }}$ in period $t \in \mathcal{T}_{T m}^{m}$ of profile $m \in \mathcal{M}$ and node $v \in \mathcal{V}$ (kWh).

$z_{i, k}^{v, m, t} \quad$ Amount of energy of type $k \in \mathcal{K}_{\text {Out }}^{i}$ generated by technology $i \in$ $\mathcal{I}_{\text {Gen }}$ in period $t \in \mathcal{T}_{T m}^{m}$ of profile $m \in \mathcal{M}$ and node $v \in \mathcal{V}(\mathrm{kWh})$.

\section{A.2 Optimisation Model}

\section{A.2.1 Strategic Constraints}

Available new technologies (devices) at each node

The number of available new devices of a given technology is equal to the number of devices installed of that technology, at any node.

$$
x_{i}^{v, a}=x i_{i}^{v} \quad \forall v \in \mathcal{V}, \quad a \in \mathcal{A}_{\text {New }}, i \in \mathcal{I}_{\text {Inv }}
$$

\section{Available old technologies (devices) at root node}

The number of devices available at the root node is equal to the number of existing devices at the start of the optimisation horizon less the number of devices decommissioned at the root node, for any technology.

$$
x_{i}^{v, a}=X Z_{i}^{a}-x d_{i}^{v, a} \quad \forall i \in \mathcal{I}, \quad a \in \mathcal{A}_{\text {Old }} \cap \mathcal{A}_{\text {Ages }}^{i, v}, v \in \mathcal{V}_{\text {Root }}
$$

\section{Available old technologies (devices) at future nodes}

The number of available devices whose age is not zero at a given node is equal 
to the number of available devices at the preceding node less the number of decommissioned devices, for any technology.

$$
x_{i}^{v, a}=x_{i}^{p a(v), a-1}-x d_{i}^{v, a} \quad \forall i \in \mathcal{I}, a \in \mathcal{A}_{\text {Old }} \cap \mathcal{A}_{\text {Ages }}^{i, v}, v \in \mathcal{V}_{\text {Fut }}
$$

\section{Technology capacity calculation}

The total capacity of a technology is equal to the sum of the number of its installed devices, corrected by their respective ageing factor and nominal capacity, at any node.

$$
x c_{i}^{v}=G_{i} \cdot \sum_{a \in \mathcal{A}_{\text {Ages }}^{i, v}} A G_{i}^{a} \cdot x_{i}^{v, a} \quad \forall i \in \mathcal{I}, v \in \mathcal{V}
$$

\section{Physical limit}

At any node, a limit may be imposed on the number of installed devices of a given technology, often dictated by the space available at the site.

$$
\sum_{a \in \mathcal{A}_{\text {Ages }}^{i, v}} x_{i}^{v, a} \leq L P_{i}^{v} \quad \forall i \in \mathcal{I}, v \in \mathcal{V}
$$

\section{Tariff choices}

Only one purchasing (sales) tariff is allowed per node and energy type.

$$
\begin{gathered}
\sum_{n \in \mathcal{N}_{\text {Pur }}^{k}} h_{k, n}^{v}=1 \quad \forall v \in \mathcal{V}, \quad k \in \mathcal{K}_{\text {Epur }} \\
\sum_{n \in \mathcal{N}_{\text {Sal }}^{k}} h_{k, n}^{v}=1 \quad \forall v \in \mathcal{V}, \quad k \in \mathcal{K}_{E S}
\end{gathered}
$$

\section{A.2.2 Operational Constraints}

\section{Output energy production}

In any short-term period, the amount of output energy produced by an energy-generating technology is calculated from the amount of input energy 
and the technology's energy-conversion factor.

$$
\begin{array}{r}
z_{i, k^{\prime}}^{v, m, t}=\sum_{k \in \mathcal{K}_{I n}^{i}} E C_{i, k, k^{\prime}}^{v} \cdot y_{i, k}^{v, m, t} \\
\forall v \in \mathcal{V}, m \in \mathcal{M}, \quad i \in \mathcal{I}_{G e n}, k^{\prime} \in \mathcal{K}_{O u t}^{i}, t \in \mathcal{T}_{T m}^{m}
\end{array}
$$

\section{Sales limit by generation capacity}

The amount of energy to be sold cannot exceed the amount of energy produced on site, at any short-term period and for any energy type.

$$
\sum_{n \in \mathcal{N}_{\text {Sal }}^{k}} w_{k, n}^{v, m, t} \leq \sum_{i \in \mathcal{I}_{\text {Gen }}} z_{i, k}^{v, m, t} \quad \forall v \in \mathcal{V}, m \in \mathcal{M}, \quad k \in \mathcal{K}_{E S}, t \in \mathcal{T}_{T m}^{m}
$$

\section{Storage available}

For any energy-storage technology, the energy available in storage at the start of a given short-term period is equal to the energy stored at the start of the previous short-term period plus the energy sent to storage minus the energy removed from storage during that period. Each type of energy flow is corrected by its respective loss ratio parameter.

$$
\begin{aligned}
r_{i, k}^{v, m, t+1} & =O S_{i, k} \cdot r_{i, k}^{v, m, t}+O I_{i, k}^{v} \cdot r i_{i, k}^{v, m, t}-O O_{i, k}^{v} \cdot r o_{i, k}^{v, m, t} \\
& \forall v \in \mathcal{V}, m \in \mathcal{M}, \quad i \in \mathcal{I}_{\text {Sto }}, t \in \mathcal{T}_{\text {Tm }}^{m}, k \in \mathcal{K}_{\text {Po }}^{i}
\end{aligned}
$$

\section{Storage level between periods}

For any energy-storage technology, the storage level at the start of the first short-term period must be equal to the storage level at the end of the last short-term period in the same operational profile and node.

$$
\begin{gathered}
r_{i, k}^{v, m, t}=O S_{i, k} \cdot r_{i, k}^{v, m, t^{\prime}}+O I_{i, k}^{v} \cdot r i_{i, k}^{v, m, t^{\prime}}-O O_{i, k}^{v} \cdot r o_{i, k}^{v, m, t^{\prime}} \\
\forall v \in \mathcal{V}, m \in \mathcal{M}, \quad i \in \mathcal{I}_{\text {Sto }}, k \in \mathcal{K}_{\text {Po }}^{i}, t \in \mathcal{T}_{\text {First }}^{m}, t^{\prime} \in \mathcal{T}_{\text {Last }}^{m}
\end{gathered}
$$

\section{Energy balance}

For each energy type, the net energy supply must meet the net energy demand in each time period. The latter consists of the energy demand less the energy saved due to passive technologies, whereas the former consists of the energy produced by energy-creating technologies plus the energy discharged from storage and the energy purchases in the energy market less the energy used 
for production or charging storage devices and the energy sold.

$$
\begin{array}{r}
\sum_{i \in \mathcal{I}_{G e n}} z_{i, k}^{v, m, t}-\sum_{i \in \mathcal{I}_{G e n}} y_{i, k}^{v, m, t}+\sum_{n \in \mathcal{N}_{P u r}^{k}} u_{k, n}^{v, m, t}-\sum_{n \in \mathcal{N}_{\text {Sal }}^{k}} w_{k, n}^{v, m, t} \\
+\sum_{i \in \mathcal{I}_{S t o}}\left(r o_{i, k}^{v, m, t}-r i_{i, k}^{v, m, t}\right)=D_{k}^{v, m, t} \cdot\left(1-\sum_{i \in \mathcal{I}_{P U}} O D_{i, k}^{v} \cdot x c_{i}^{v}\right) \\
\forall k \in \mathcal{K}, v \in \mathcal{V}, m \in \mathcal{M}, t \in \mathcal{T}_{T m}^{m}
\end{array}
$$

\section{A.2.3 Strategic-Operational Constraints}

\section{Technology output limit}

In any period, the amount of energy that can be produced by a technology is constrained by the technology's availability and capacity.

$$
\begin{array}{r}
z_{i, k}^{v, m, t} \leq D T^{m} \cdot A F_{i}^{v, m, t} \cdot x c_{i}^{v} \\
\forall v \in \mathcal{V}, m \in \mathcal{M}, \quad i \in \mathcal{I}_{G e n}, k \in \mathcal{K}_{P o}^{i}, t \in \mathcal{T}_{T m}^{m}
\end{array}
$$

\section{Storage (dis)charge limit}

In any period, the amount of energy that can be discharged from (charged into) a given energy-storage technology is limited by the technology's installed capacity and maximum discharge (charge) rate.

$$
\begin{array}{r}
r o_{i, k}^{v, m, t} \leq O X_{i, k}^{v} \cdot D T^{m} \cdot x c_{i}^{v} \\
\forall v \in \mathcal{V}, m \in \mathcal{M}, \quad i \in \mathcal{I}_{S t o}, t \in \mathcal{T}_{T m}^{m}, k \in \mathcal{K}_{P o}^{i} \\
\forall v \in \mathcal{V}, m \in \mathcal{M}, \quad i \in \mathcal{I}_{\text {Sto }}, t \in \mathcal{T}_{T m}^{v, m, t}, k \in \mathcal{K}_{P o}^{i}
\end{array}
$$

\section{Lower and upper storage limits}

In any period, the amount of energy that can be stored in any energy-storage technology must be greater (lower) than the capacity installed corrected by the respective minimum (maximum) charge ratio.

$$
r_{i, k}^{v, m, t} \geq O A_{i, k}^{v} \cdot x c_{i}^{v} \quad \forall v \in \mathcal{V}, m \in \mathcal{M}, \quad i \in \mathcal{I}_{S t o}, t \in \mathcal{T}_{T m}^{m}, k \in \mathcal{K}_{P o}^{i}
$$




$$
r_{i, k}^{v, m, t} \leq O B_{i, k}^{v} \cdot x c_{i}^{v} \quad \forall v \in \mathcal{V}, m \in \mathcal{M}, \quad i \in \mathcal{I}_{S t o}, t \in \mathcal{T}_{T m}^{m}, k \in \mathcal{K}_{P o}^{i}
$$

\section{Purchasing and sales limits by contract}

For any tradable energy type, the amount of energy that can be purchased (sold) in a given period must not exceed the amount stipulated in the signed purchase (sales) contract.

$$
\begin{array}{r}
u_{k, n}^{v, m, t} \leq h_{k, n}^{v} \cdot M E_{k, n} \cdot D T^{m} \\
\forall v \in \mathcal{V}, m \in \mathcal{M}, \quad k \in \mathcal{K}_{E p u r}, n \in \mathcal{N}_{\text {Pur }}^{k}, t \in \mathcal{T}_{T m}^{m} \\
\forall v \in \mathcal{V}, m \in \mathcal{M}, \quad k \in \mathcal{K}_{E S}^{v, m, t} \leq h_{k, n}^{v} \cdot M E_{k, n} \cdot D T^{m} \\
\forall \mathcal{N}_{\text {Sal }}^{k}, t \in \mathcal{T}_{T m}^{m}
\end{array}
$$

\section{A.2.4 Performance Constraints}

\section{Primary energy consumption}

For each node, the primary energy consumed is equal to the sum of the amount of energy purchased of each type adjusted by the respective off-site energy-conversion factor.

$$
e n^{v}=\sum_{m \in \mathcal{M}} D M^{m} \cdot \sum_{t \in \mathcal{T}_{T m}^{m}}\left(\sum_{k \in \mathcal{K}_{E p u r}, n \in \mathcal{N}_{P u r}^{k}} B_{k, n} \cdot u_{k, n}^{v, m, t}\right) \forall v \in \mathcal{V}
$$

\section{Energy consumption limit}

The amount of energy consumed at a given node must not exceed a specified limit.

$$
e n^{v} \leq E L^{v} \quad \forall v \in \mathcal{V}
$$

\section{Total expected primary energy consumption}

$$
e t=\sum_{v \in \mathcal{V}} P R^{v} \cdot e n^{v}
$$

\section{Total emissions of a pollutant}

The pollution emissions consist of the emissions by energy purchases and 
energy-generating technologies, at any node and for any pollutant.

$$
\begin{aligned}
p n_{\ell}^{v}= & \sum_{m \in \mathcal{M}} D M^{m} \cdot \sum_{t \in \mathcal{T}_{T m}^{m}}\left(\sum_{i \in \mathcal{I}_{G e n}, k \in \mathcal{K}_{I n}^{i}} L H_{k, \ell}^{v} \cdot y_{i, k}^{v, m, t}\right. \\
& \left.+\sum_{k \in \mathcal{K}_{\text {Epur }}, n \in \mathcal{N}_{P u r}^{k}} L C_{k, \ell, n}^{v} \cdot u_{k, n}^{v, m, t}\right) \quad \forall \ell \in \mathcal{L}, v \in \mathcal{V}
\end{aligned}
$$

\section{Pollution emissions limit}

The total emissions of a given pollutant may not exceed a specified limit, at any node.

$$
p n_{\ell}^{v} \leq P L_{\ell}^{v} \quad \forall \ell \in \mathcal{L}, v \in \mathcal{V}
$$

\section{Total expected pollution emissions}

$$
p=\sum_{v \in \mathcal{V}} P R^{v} \cdot \sum_{\ell \in \mathcal{L}} p n_{\ell}^{v}
$$

\section{Total cost}

For each node, the total cost is composed of the net investment, decommissioning, maintenance, energy trading, and technology operation costs. 


$$
\begin{aligned}
c n^{v}= & \sum_{i \in \mathcal{I}_{\text {Inv }}}\left(C I_{i}^{v}-S U_{i}^{v}\right) \cdot G_{i} \cdot x i_{i}^{v}+\sum_{i \in \mathcal{I}} \sum_{a \in \mathcal{A}_{A g e s}^{i, v}} C D_{i}^{v, a} \cdot G_{i} \cdot x d_{i}^{v, a} \\
& +\sum_{i \in \mathcal{I}} C M_{i}^{v} \cdot G_{i} \cdot \sum_{a \in \mathcal{A}_{A g e s}^{i, v}} x_{i}^{v, a} \\
& +\sum_{k \in \mathcal{K}_{E p u r}, n \in \mathcal{N}_{P u r}^{k}} \sum_{m \in \mathcal{M}} D M^{m} \cdot \sum_{t \in \mathcal{T}_{T m}^{m}} P P_{k, n}^{v, m, t} \cdot u_{k, n}^{v, m, t} \\
& -\sum_{k \in \mathcal{K}_{E S}, n \in \mathcal{N}_{S a l}^{k}} \sum_{m \in \mathcal{M}} D M^{m} \cdot \sum_{t \in \mathcal{T}_{T m}^{m}} S P_{k, n}^{v, m, t} \cdot w_{k, n}^{v, m, t} \\
& +\sum_{i \in \mathcal{I}_{G e n}} \sum_{m \in \mathcal{M}} D M^{m} \cdot \sum_{t \in \mathcal{T}_{T m}^{m}} C O_{i, k}^{v} \cdot z_{i, k}^{v, m, t} \\
& +\sum_{i \in \mathcal{I}_{S t o}} \sum_{m \in \mathcal{M}} D M^{m} \cdot \sum_{t \in \mathcal{T}_{T m}^{m}} C O_{i, k}^{v} \cdot r O_{i, k}^{v, m, t} \quad \forall v \in \mathcal{V}
\end{aligned}
$$

\section{Total discounted expected cost}

$$
c=\sum_{v \in \mathcal{V}}(1+D R)^{-P T^{v}} \cdot P R^{v} \cdot c n^{v}
$$

\section{CVaR calculation}

Eq. (28) calculates the CVaR at a confidence level of $A L \times 100 \%$.

$$
r t=v r+(1-A L)^{-1} \cdot \sum_{s \in \mathcal{S}} P R^{l f(s)} \cdot s r^{s}
$$

\section{Risk constraints}

Eq. (29) sets a lower limit on the auxiliary variable $s r^{s} \in \mathbb{R}^{+}, s \in \mathcal{S}$, which is necessary for calculating the CVaR of the discounted costs.

$$
\sum_{v \in \mathcal{V}_{\text {Path }}^{s}}(1+D R)^{-P T^{v}} \cdot c n^{v}-v r \leq s r^{s} \quad \forall s \in \mathcal{S}
$$




\section{A.2.5 Objective Function}

In our strategic optimisation model, we consider a mean-risk objective function, i.e., the goal is to minimise a weighted average of the expected value and CVaR of the total discounted cost:

$$
\text { Minimise } \quad(1-B E) \cdot c+B E \cdot r t
$$

subject to constraints (1)-(29).

\section{Appendix B Input Parameters of Numerical Examples}

In this appendix, we describe the main input parameters used in Section 3. Unless otherwise indicated in Section 3, these are valid for every regulatory setting of a given site. The input parameters are calibrated in order to yield the same energy balances as those observed for the test buildings in the current year. For FASAD, the parameter values for new equipment are collected from energy-industry catalogues, whereas the values reported in Groissböck et al. (2014) are used for Pinkafeld.

\section{B.1 FASAD}

Table 5: Energy-Generation Technology Parameters for FASAD

\begin{tabular}{lllrcccc}
\hline$i$ & $\mathcal{K}_{\text {In }}$ & $\mathcal{K}_{\text {Out }}$ & $\begin{array}{c}C I^{0} \\
(€ / \mathrm{kW})\end{array}$ & $\begin{array}{c}C M \\
(€ / \mathrm{kW})\end{array}$ & $E C$ & $\begin{array}{c}G \\
(\mathrm{~kW})\end{array}$ & $\begin{array}{c}\text { LH } \\
(\mathrm{kg} / \mathrm{kWh})\end{array}$ \\
\hline boiler 1 & natural gas & heat & 9.32 & 0 & 0.925 & 1279.1 & 0.1836 \\
boiler 2 & natural gas & heat & 14.14 & 0 & 0.92 & 232.6 & 0.1836 \\
CHP & natural gas & electricity & 5255.0 & 0 & 0.268 & 5.5 & 0.1836 \\
& & heat & & & 0.61 & & \\
PV & solar radiation & electricity & 1920.0 & 0 & 0.146 & 0.245 & 0 \\
ST & solar radiation & heat & 686.8 & 0 & 0.788 & 1.998 & 0 \\
\hline
\end{tabular}


Table 6: Thermal Storage Parameters for FASAD

\begin{tabular}{lr}
\hline parameter & value \\
\hline$C I^{0}(€ / \mathrm{kWh})$ & 100.00 \\
$O A$ & 0.00 \\
$O B$ & 1.00 \\
$O I$ & 0.90 \\
$O O$ & 1.00 \\
$O S$ & 0.99 \\
$O X(\mathrm{~kW} / \mathrm{kWh})$ & 0.25 \\
$O Y(\mathrm{~kW} / \mathrm{kWh})$ & 0.25 \\
\hline
\end{tabular}

Table 7: Lighting Replacement Parameters for FASAD

\begin{tabular}{lcc}
\hline$k$ & $C I^{0}(€)$ & $O D$ \\
\hline electricity & 14200 & 0.1385 \\
\hline
\end{tabular}

Table 8: Energy Tariff Parameters for FASAD

\begin{tabular}{|c|c|c|c|c|c|c|c|}
\hline$k$ & $n$ & type & $B$ & $\begin{array}{c}L C \\
(\mathrm{~kg} / \mathrm{kWh})\end{array}$ & $\begin{array}{c}M E \\
(\mathrm{~kW})\end{array}$ & $\begin{array}{c}P P^{0} \\
(€ / \mathrm{kWh})\end{array}$ & $\begin{array}{c}S P^{0} \\
(€ / \mathrm{kWh})\end{array}$ \\
\hline electricity & flat tariff & purchase & 2.0624 & 0.37 & 100.0 & 0.1426 & \multirow{4}{*}{0.1721} \\
\hline electricity & feed-in tariff & sale & & & 5.5 & & \\
\hline natural gas & flat tariff & purchase & 1 & 0 & 1426.3 & 0.0523 & \\
\hline solar radiation & & purchase & 0 & 0 & & 0 & \\
\hline
\end{tabular}

Table 9: Annual Growth Rate of FASAD's Random Parameters

\begin{tabular}{lcc}
\hline parameter & mean & volatility \\
\hline electricity prices & $7.6 \%$ & $4.3 \%$ \\
energy demands & $0.0 \%$ & $1.0 \%$ \\
installation costs & $0.0 \%$ & $1.0 \%$ \\
natural gas prices & $9.6 \%$ & $6.9 \%$ \\
\hline
\end{tabular}




\section{B.2 Pinkafeld}

Table 10: Energy-Generation Technology Parameters for Pinkafeld

\begin{tabular}{lllccccc}
\hline$i$ & $\mathcal{K}_{\text {In }}$ & $\mathcal{K}_{\text {Out }}$ & $\begin{array}{c}C I^{0} \\
(€ / \mathrm{kW})\end{array}$ & $\begin{array}{c}C M \\
(€ / \mathrm{kW})\end{array}$ & $E C$ & $\begin{array}{c}G \\
(\mathrm{~kW})\end{array}$ & $\begin{array}{c}\text { LH } \\
(\mathrm{kg} / \mathrm{kWh})\end{array}$ \\
\hline HVAC & electricity & cooling & 1000.0 & 0.0139 & 3.5 & 79.80 & 0 \\
PV & solar radiation & electricity & 2331.1 & 0.1740 & 0.125 & 1.28 & 0 \\
ST & solar radiation & heat & 358.0 & 0.107 & 0.5 & 1.00 & 0 \\
\hline
\end{tabular}

Table 11: Thermal Storage Parameters for Pinkafeld

\begin{tabular}{lr}
\hline parameter & value \\
\hline$C I^{0}(€ / \mathrm{kWh})$ & 71.62 \\
$O A$ & 0.00 \\
$O B$ & 1.00 \\
$O I$ & 0.90 \\
$O O$ & 1.00 \\
$O S$ & 0.99 \\
$O X(\mathrm{~kW} / \mathrm{kWh})$ & 0.25 \\
$O Y(\mathrm{~kW} / \mathrm{kWh})$ & 0.25 \\
\hline
\end{tabular}

Table 12: Energy Tariff Parameters for Pinkafeld

\begin{tabular}{llllllll}
\hline$k$ & $n$ & type & $B$ & $\begin{array}{c}L C \\
(\mathrm{~kg} / \mathrm{kWh})\end{array}$ & $\begin{array}{c}M E \\
(\mathrm{~kW})\end{array}$ & $\begin{array}{c}P P^{0} \\
(€ / \mathrm{kWh})\end{array}$ & $\begin{array}{c}S P^{0} \\
(€ / \mathrm{kWh})\end{array}$ \\
\hline $\begin{array}{lllllll}\text { district heating } \\
\text { electricity }\end{array}$ & flat tariff & purchase & 2.0 & 0.03 & 120.0 & 0.08028 & \\
electricity & flat tariff & purchase & 1.089 & 0.03 & 100.0 & 0.15 & \\
solar radiation & flat tariff & sale & & & 100.0 & & 0.0759 \\
\hline
\end{tabular}

Table 13: Annual Growth Rate of Pinkafeld's Random Parameters

\begin{tabular}{lcc}
\hline parameter & mean & volatility \\
\hline district heating prices & $3.4 \%$ & $6.1 \%$ \\
electricity prices & $5.3 \%$ & $7.8 \%$ \\
energy demand & $0.0 \%$ & $1.0 \%$ \\
installation costs & $0.0 \%$ & $1.0 \%$ \\
\hline
\end{tabular}

